\title{
Analysis of 3D Semi-Elliptical Crack on Reactor Pressure Vessel Wall with Load Stress and Crack Ratio
}

\author{
Mike Susmikanti", Roziq Himawan, Entin Hartini, Rokhmadi \\ Center for Nuclear Reactor Technology and Safety, National Nuclear Energy Agency, Puspiptek Area,Tangerang, 15310 Indonesia
}

\section{ARTICLE INFO}

Article history:

Received: 22 January 2019

Received in revised form: 20 February 2019

Accepted: 26 February 2019

Keywords:

Semi Elliptic Surface Crack

3-Dimension

Reactor Pressure Vessel

Elastic-plastic fracture mechanics

J-integral

\begin{abstract}
A B S T R A C T
Reactor Pressure Vessel (RPV) wall is an important component in the Nuclear Power Plant (NPP). During reactor operation, RPV is subjected to high temperature, pressure, and neutron exposure. This condition could lead to RPV structure failure. In order to assure the integrity of RPV during the reactor lifetime, it is mandatory to perform a structural integrity assessment of RPV by evaluating postulated crack in RPV. In the previous study, the crack has evaluated in 2-D. However, 3-D analysis of semi-elliptic crack shape in the surface of the thick plate for RPV wall using SA 508 Steel is yet to be analyzed. The objective of this study is to analyze and modeling the evaluation in variation crack ratio with some load stress in 3-D. The Stress Intensity Factor (SIF) and Jintegral are used as crack parameter. The J-Integral were calculated using MSC MARC MENTAT based on Finite Element Method (FEM) for obtaining the SIF value. The inputs are a crack ratio, load stress, material property, and geometry. The modeling of SIF value and goodness of fit are using MINITAB. The fracture condition could be predicted in comparison to the SIF value and fracture toughness. For the load stress $70 \mathrm{MPa}$ and $80 \mathrm{MPa}$, with a crack ratio $0.25,0.33$ and 0.5 , the material on RPV wall will in fracture condition.
\end{abstract}

(C) 2019 Tri Dasa Mega. All rights reserved.

\section{INTRODUCTION}

Reactor Pressure Vessel (RPV) is an important structure in the Nuclear Power Plant (NPP). As a pressure boundary which confines radioactive material, its material degradation becomes important issue in term of structural integrity. During reactor operation, RPV is subjected to high temperature and high pressure, as well as high neutron exposure. This condition may lead to RPV structure failure.

In order to assure the integrity of RPV during reactor lifetime, it is mandatory to perform a structural integrity assessment of RPV. Crack assessment which considers the real condition is a complex problem. For example, neutron

\footnotetext{
${ }^{*}$ Corresponding author. Tel./Fax.: +62-21-7560912

E-mail: mike@batan.go.id DOI: $10.17146 / \mathrm{tdm} .2019 .21 .1 .5306$
}

embrittlement, crack geometry, load types, the presence of cladding, etc. should be considered in the assessment in order to get an accurate remaining life of the RPV. Moreover, parameters used in the assessment are equally important. Crack geometry could be described as crack ratio either the ratio of crack depth to surface crack length and/or the ratio of crack depth to specimen thickness. Meanwhile, load are divided into external and internal loads. An internal load may be caused by external loads, including stress loads.

Various studies concerning crack loads have been performed, for example the crack of beam structures using a new cracked Euler-Bernoulli beam element, using Genetic Algorithm detection [1]. The 3-D SIF analysis was performed for inner radial or coplanar crack arrays and ring cracks in a spherical pressure vessel [2]. Moreover, the effects 
of tempering PWHT was analyzed on microstructures and mechanical properties of SA508 GR.4N steel [3]. Failure analysis was performed by using fracture mechanic [4]. The SIF for mode-I fatigue crack was determined based on finite element [5]. Furthermore, the 3-D Stress Intensity Factors was calculated to full autofrettage for inner radial or coplanar crack arrays and ring cracks in a spherical pressure vessel [6]. Meanwhile a simple method was used for calculating the stress intensity factors for complex 3D cracks at a notch [7]. Stress intensity factors for semi-elliptical cracks with high aspect ratios were computed by using the tetrahedral finite element [8]. Stress intensity factors were calculated for embedded elliptical cracks in cylindrical and spherical vessels [9]. Furthermore, the mechanical fracture of PWR Pressure Vessel was evaluated and modeling based on Neural Network [10]. The uncertainty of fracture mechanic was analyzed in the reliability assessment for the RPV (2D) subjected to the internal pressure [11]. Finally, the crack Ratio for PWR Pressure Vessel Cladding was optimized using Genetic Algorithm [12].

None of the aforementioned studies, especially for calculated the SIF value with a semi-elliptic surface crack shape in 3-D thick plate, have been performed for material SA 508 which use in RPV wall. The SIF calculated for semi-elliptic crack with a ratio of crack depth and the width crack are yet to be analyzed as well. There were also no modelling on SIF value concerning variation crack ratio and some load stress.

The objective of this study is to analyze a fracture mechanic of the 3-D thick plate with the semi-elliptic surface crack shape for material SA 508 in RPV wall in several load stress and various crack ratio. The SIF values will be compared to the fracture toughness value of the material to know whether material may be fractured or not. Therefore, the SIF value will also modeled in various ratio for ratio crack depth and surface length with several load stress.

The goodness of fit results of the relationship was obtained between crack ratio and load stress. The SIF value was modeled in various crack depth and surface length with several load stress in order to understand whether the material of the RPV wall is in fracture condition or not.

\section{THEORY}

Fracture Mechanic is the field of mechanics concerned with the study of material strength in the presence of a crack. In elastic-plastic fracture mechanic, where crack-tip deformation no longer obeys the linear-elastic approximation, J-Integral could be used to measure toughness of a material. Calculation of J-Integral then could be converted into SIF, according to the empirical equation. Critical crack size in the material was determined by comparing the value of SIF and the fracture toughness of the material. If the SIF still less than the Fracture Toughness, it means the material still has resistance against fracture. Thus, crack propagation still take place under a stable regime. The fracture toughness, $K_{I C}$, is a material property which describes the ability of a material containing a crack to resist fracture. The model of the semielliptic crack in the form of three-dimensional (3D) is shown in Fig. $1[2,6,7]$.

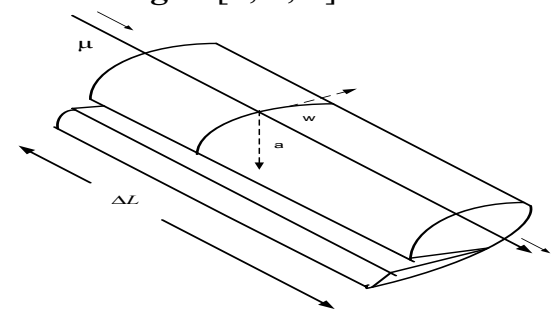

Fig.1. The elliptic crack in 3-D

The stress intensity factor, $K_{I}$, is a fracture mechanic parameter to predict the stress state near the tip of a crack caused by a load. The value of stress intensity factor is governed by stress level, crack geometry and material geometry. In the crack analysis, stress intensity factor is compared to fracture toughness. The stability of crack propagation could be determined by comparing the value of $K_{I}$ and $K_{I C}$. Since the value $K_{I}$ is smaller than $K_{I C}$, it means that the material of structure is still under safe condition. Conversely, the material of structure will experience fracture if the $K_{I}$ value is equal or larger than $K_{I C}$ values. $K_{I}$ is a function of the elliptic crack $a$, and the working stress $\sigma$ varies with the type of the crack front and stress. The Stress Intensity Factor is expressed by Eq. 1[4],

$$
K_{I}=\sigma \sqrt{\pi a} \cdot f(a / W)
$$

which $\sigma$ is the nominal stress, $a$ is the depth crack, $W$ is the width of the specimen, and $f(a / W)$ is a function depends on the ratio of crack depth and the width of the specimen.

In this study, the elastic plastic fracture mechanics was considered, so that SIF is unable to be directly used to evaluate crack. In elastic plastic fracture mechanic, J-integral was used to evaluate the crack. The value of J-Integral was evaluated around crack front in the form of the stress value. The J-integral can be modified numerically or with finite element method. The weighted average J- 
Integral over the crack front around segment $\Delta L$ is expressed in Eq. 2 [10, 11, 12],

$$
J \Delta L=\int_{\Delta L} J(\mu) q d \mu
$$

where $q$ is the ratio of $\Delta L / \Delta a, \Delta L$ is a length of specimens and $\Delta a$ is a crack depth. $J(\mu)$ is the pointwise value of the integral path which containing the crack tip, and $q$ is the weighted function.

After obtaining J-integral value, the SIF can be found by using relationship equation between stress intensity factor and J-integral, as expressed by Eq. $3[10,11,12]$,

$$
K_{I}=\sqrt{\frac{E}{1-v^{2}} J}
$$

where $E$ is modulus Young, $v$ is the value of Poisson ratio, $J$ is the value of the J-Integral.

\section{METHODOLOGY}

In this study, J-integral calculations of crack in RPV wall were modeled as a rectangular plate with semi elliptic surface crack as shown in Fig. 2. In this research, the material type used for RPV is ferritic steel SA 508. Table 1 showed the chemical composition of SA 508 [3]. The sample geometry has a length of $1200 \mathrm{~mm}$, width of $600 \mathrm{~mm}$ and depth of $300 \mathrm{~mm}$, respectively. The poisson ratio $(v)$ is 0.3 and modulus Young (E) is $187 \times 10^{3}$ $\mathrm{MPa}[10,12]$.

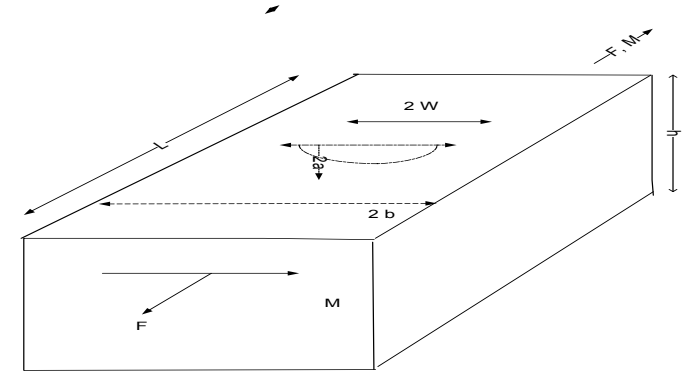

Fig. 2. The sample geometry in 3-D

The 3-D fracture analysis were performed through J-Integral calculations based on Finite Element Method (FEM) by MARC MENTAT software. The flow of fracture analysis described in Fig. 3. The parameter inputs were length, width, and thickness of the plate. The material properties are Poisson ratio and modulus Young. The semielliptic crack front were given in edge geometry and boundary condition. The calculation of SIF were obtained in numerically according to Eq. (1) and (3). In order to evaluate the relationship between load and crack geometry, the J-integral calculation were performed by varying load and crack ratio.
Table 1. The composition elements of steel SA 508 [3]

\begin{tabular}{cc}
\hline Element & Weight (\%) \\
\hline $\mathrm{C}$ & 0.21 \\
$\mathrm{Si}$ & 0.27 \\
$\mathrm{Mn}$ & 0.69 \\
$\mathrm{P}$ & 0.005 \\
$\mathrm{~S}$ & 0.004 \\
$\mathrm{Ni}$ & 0.78 \\
$\mathrm{Cr}$ & 0.38 \\
$\mathrm{Mo}$ & 0.63 \\
$\mathrm{Al}$ & 0.15 \\
$\mathrm{Cu}$ & 0.16 \\
\hline
\end{tabular}

The loads applied to the specimen were varied between 35 to $80 \mathrm{MPa}$. The load variation was determined based on the assumption that the fracture toughness for material SA 508 from experimental's results are in range 25 to $100 \mathrm{MPa}$ [3]. The crack ratio $a / W$ (crack depth to surface crack length) and $a / h$ (crack depth to specimen thickness) were varied between 0.25 and 1 .

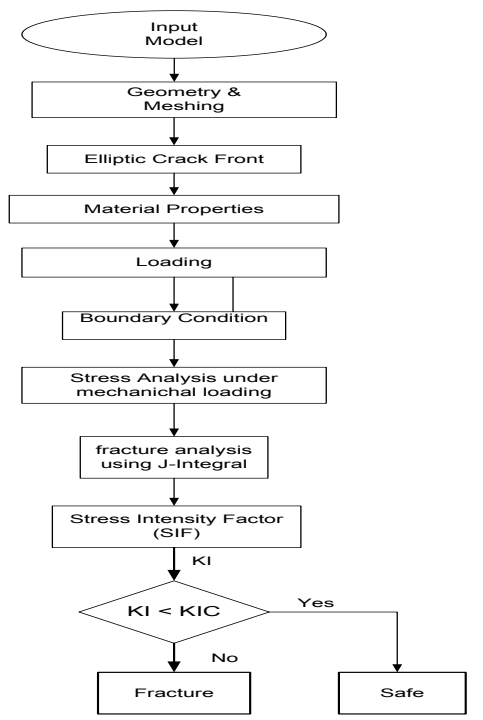

Fig. 3. Fracture Mechanic Analysis

In order to assure the safety of Nuclear Power Plant operation, it is mandatory to perform structural integrity assessment periodically. By determining SIF with various load level and crack geometry, we can construct a relationship between SIF and crack length.

\section{RESULTS AND DISCUSSION}

The J-integral is a constant value used to evaluate the circumference of elliptic crack front in relation to the stress value. This value has a relation with SIF calculation or stress value. The J-integral value depends on the integral path taken in the calculation. The variation of J-integral value could be seen in different nodes near the crack front. The crack ratio $a / W$ is the ratio of depth crack (a) and 
width crack $(W)$. The ratio $a / h$ is the ratio of depth crack (a) and surface length $(h)$.

Fig. 4 showed an example of the J-integral calculation result. The sample geometry is 1200 $\mathrm{mm}$ in length, $600 \mathrm{~mm}$ width, and $300 \mathrm{~mm}$ depth. The Poisson ratio $(v)$ was 0.3 and modulus young (E) is $187 \times 10^{3} \mathrm{MPa}$. Under stress $\sigma$ is $40 \mathrm{MPa}$, crack ratio $\mathrm{a} / \mathrm{W}$ is $0.25(\mathrm{a}=1$ and $\mathrm{W}=4)$ and crack depth to specimen thickness ratio $\mathrm{a} / \mathrm{h}=0.33$ (Table 3).

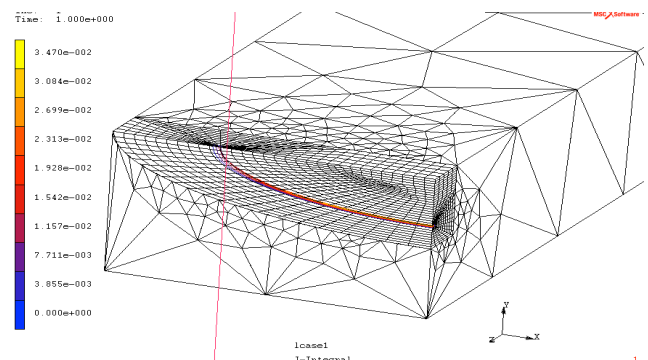

Fig. 4. The J-Integral in elliptic crack $a / W=0.25$ and $\mathrm{a} / \mathrm{h}=0.33$

The $\mathrm{a} / \mathrm{h}$ parameter was assumed constant for several crack ratio a/W. The J-Integral value over the crack front around segment is 0.03470 . The weighted average J-Integral over the crack front around the segment. The J-integral value is indicated in red color along the crack front. The variation of J-integral is shown from the blue color to the red color in contour-line. The blue color indicates the minimum value of J-integral value over the crack front around segment, 0.003855 .

Meanwhile, the red color indicates the maximum value of J-integral value over the crack front around segment, 0.03470. In SIF calculation, the maximum value of J-integral was used. For the J-integral 0.03470 , the value of SIF is 84.44 MPa $\sqrt{m}$ (Table 4). Compared to the fracture toughness (100 MPa $\sqrt{m}$ ) [10], the SIF value is still below the fracture toughness. It means that, the presence of crack under this condition, crack propagation undergo in a stable manner, therefore material fracture could be avoided.

Fig. 5 and Fig. 6 showed another J-integral calculation results, with the same load level but different crack ratio, where $\mathrm{a} / \mathrm{W}$ is 0.33 ( $\mathrm{a}=1$ and $\mathrm{W}=3)$ and $0.5(\mathrm{a}=1$ and $\mathrm{W}=2)$, the $\mathrm{J}$-Integral value each are 0.02754 and 0.02100 and the SIF values are of 75.22 $M P a \sqrt{m}$ and $65.69 M P a \sqrt{m}$, respectively.

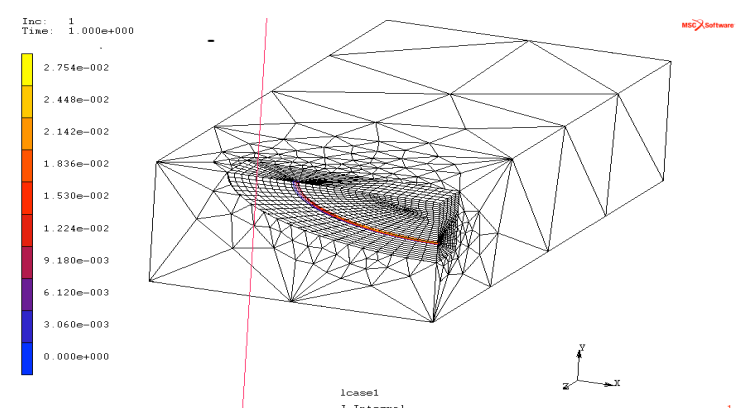

Fig. 5. The J-Integral in elliptic crack $a / W=0.33$ and a/h $=0.33$

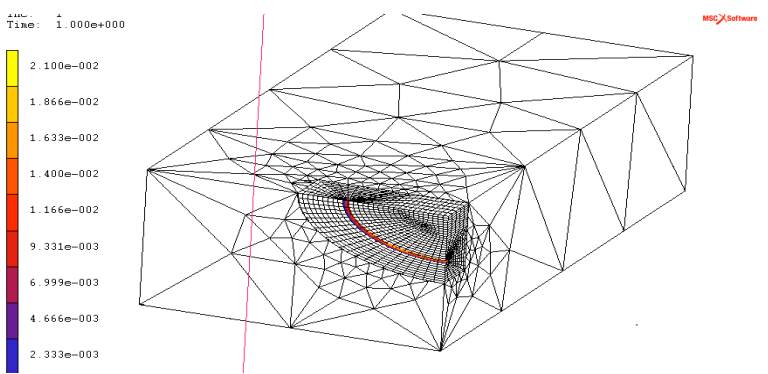

Fig. 6. The J-Integral in elliptic crack $a / W=0.5$ and a/h $=0.33$

The SIF for crack ratio $0.25,0.33$ and 0.5 each are 84.44 MPa $\sqrt{m}, 75.22 M P a \sqrt{m}$ and 65.69 $\mathrm{MPa} \sqrt{\mathrm{m}}$. Sorted from the largest crack surface length are $0.25,0.33$ and 0.5 , respectively. It means that the SIF will increase in linear with crack surface length. Several data set are described in Table 2 until Table 6. The load stress $\sigma$ each 35, 40, 60, 70 and $80 \mathrm{MPa}$, respectively.

Table 2. Stress $\sigma=35 \mathrm{MPa}$

\begin{tabular}{cccccc}
\hline $\begin{array}{c}\text { a } \\
\text { (depth } \\
\text { crack) }\end{array}$ & $\begin{array}{c}\text { W } \\
\text { (width } \\
\text { crack) }\end{array}$ & $\begin{array}{c}\text { a/ } \mathbf{W} \\
\text { (ratio) }\end{array}$ & $\begin{array}{c}\text { a/h } \\
\text { (ratio) }\end{array}$ & $\begin{array}{c}\text { J-Int. } \\
\left(\mathbf{J}_{\mathbf{I}}\right)\end{array}$ & $\begin{array}{c}\text { SIF } \\
\left(\mathbf{K}_{\mathbf{I}}\right)\end{array}$ \\
\hline 1 & 2 & 0.50 & 0.33 & 0.01457 & 54.71 \\
1 & 3 & 0.33 & 0.33 & 0.01912 & 62.68 \\
1 & 4 & 0.25 & 0.33 & 0.02408 & 70.43 \\
1.5 & 2 & 0.75 & 0.50 & 0.01032 & 46.05 \\
1.5 & 3 & 0.50 & 0.50 & 0.01422 & 54.05 \\
1.5 & 4 & 0.37 & 0.50 & 0.01751 & 59.98 \\
2.0 & 2 & 1.00 & 0.67 & 0.00963 & 44.48 \\
2.0 & 3 & 0.67 & 0.67 & 0.01083 & 47.17 \\
2.0 & 4 & 0.50 & 0.67 & 0.01367 & 53.00 \\
\hline
\end{tabular}

Table 3. Stress $\sigma=\mathbf{4 0} \mathrm{MPa}$

\begin{tabular}{cccccc}
\hline $\begin{array}{c}\text { a } \\
\text { (depth } \\
\text { crack) }\end{array}$ & $\begin{array}{c}\mathbf{W} \\
\text { (width } \\
\text { crack) }\end{array}$ & $\begin{array}{c}\mathbf{a} / \mathbf{W} \\
\text { (ratio) }\end{array}$ & $\begin{array}{c}\mathbf{a} / \mathbf{h} \\
\text { (ratio) }\end{array}$ & $\begin{array}{c}\text { J-Int. } \\
\left(\mathbf{J}_{\mathrm{I}}\right)\end{array}$ & $\begin{array}{c}\text { SIF } \\
\left(\mathbf{K}_{\mathrm{I}}\right)\end{array}$ \\
\hline 1 & 2 & 0.50 & 0.33 & 0.02100 & 65.69 \\
1 & 3 & 0.33 & 0.33 & 0.02754 & 75.22 \\
1 & 4 & $\mathbf{0 . 2 5}$ & $\mathbf{0 . 3 3}$ & $\mathbf{0 . 0 3 4 7 0}$ & $\mathbf{8 4 . 4 4}$ \\
1.5 & 2 & 0.75 & 0.50 & 0.01487 & 55.24 \\
1.5 & 3 & 0.50 & 0.50 & 0.02340 & 69.34 \\
1.5 & 4 & 0.37 & 0.50 & 0.02522 & 71.99 \\
2.0 & 2 & 1 & 0.67 & 0.01387 & 53.38 \\
2.0 & 3 & 0.67 & 0.67 & 0.01561 & 56.63 \\
2.0 & 4 & 0.50 & 0.67 & 0.01969 & 58.93 \\
\hline
\end{tabular}


Table 4. Stress $\sigma=60 \mathrm{MPa}$

\begin{tabular}{cccccc}
\hline $\begin{array}{c}\text { a } \\
\text { (depth } \\
\text { crack) }\end{array}$ & $\begin{array}{c}\text { W } \\
\text { (width } \\
\text { crack) }\end{array}$ & $\begin{array}{c}\mathbf{a} / \mathbf{W} \\
\text { (ratio) }\end{array}$ & $\begin{array}{c}\text { a/h } \\
\text { (ratio) }\end{array}$ & $\begin{array}{c}\text { J-Int. } \\
\left(\mathbf{J}_{\mathrm{I}}\right)\end{array}$ & $\begin{array}{c}\text { SIF } \\
\left(\mathbf{K}_{\mathrm{I}}\right)\end{array}$ \\
\hline 1 & 2 & 0.50 & 0.33 & 0.05837 & 109.51 \\
1 & 3 & 0.33 & 0.33 & 0.07656 & 125.43 \\
1 & 4 & 0.25 & 0.33 & 0.09648 & 140.80 \\
1.5 & 2 & 0.75 & 0.50 & 0.04135 & 92.18 \\
1.5 & 3 & 0.50 & 0.50 & 0.05655 & 107.80 \\
1.5 & 4 & 0.37 & 0.50 & 0.07013 & 120.04 \\
2.0 & 2 & 1.00 & 0.67 & 0.03857 & 89.02 \\
2.0 & 3 & 0.67 & 0.67 & 0.04342 & 94.46 \\
2.0 & 4 & 0.50 & 0.67 & 0.05472 & 106.04 \\
\hline
\end{tabular}

Table 5. Stress $\sigma=70 \mathrm{MPa}$

\begin{tabular}{cccccc}
\hline $\begin{array}{c}\text { a } \\
\text { (depth } \\
\text { crack) }\end{array}$ & $\begin{array}{c}\mathbf{W} \\
\text { (width } \\
\text { crack) }\end{array}$ & $\begin{array}{c}\mathbf{a} / \mathbf{W} \\
\text { (ratio) }\end{array}$ & $\begin{array}{c}\mathbf{a} / \mathbf{h} \\
\text { (ratio) }\end{array}$ & $\begin{array}{c}\text { J-Int. } \\
\left(\mathbf{J}_{\mathrm{I}}\right)\end{array}$ & $\begin{array}{c}\text { SIF } \\
\left(\mathbf{K}_{\mathrm{I}}\right)\end{array}$ \\
\hline 1 & 2 & 0.50 & 0.33 & 0.08407 & 131.44 \\
1 & 3 & 0.33 & 0.33 & 0.11103 & 151.04 \\
1 & 4 & 0.25 & 0.33 & 0.14020 & 169.00 \\
1.5 & 2 & 0.75 & 0.50 & 0.05956 & 110.63 \\
1.5 & 3 & 0.50 & 0.50 & 0.08145 & 129.37 \\
1.5 & 4 & 0.37 & 0.50 & 0.09000 & 135.99 \\
2.0 & 2 & 1.00 & 0.67 & 0.04387 & 94.94 \\
2.0 & 3 & 0.67 & 0.67 & 0.06561 & 116.11 \\
2.0 & 4 & 0.50 & 0.67 & 0.07881 & 127.26 \\
\hline
\end{tabular}

Table 6. Stress $\sigma=80 \mathrm{MPa}$

\begin{tabular}{llllll}
\hline $\begin{array}{c}\text { a } \\
\text { (depth } \\
\text { crack) }\end{array}$ & $\begin{array}{c}\text { W } \\
\text { (width } \\
\text { crack) }\end{array}$ & $\begin{array}{c}\mathbf{a} / \mathbf{W} \\
\text { (ratio) }\end{array}$ & $\begin{array}{c}\mathbf{a} / \mathbf{h} \\
\text { (ratio) }\end{array}$ & $\begin{array}{c}\text { J-Int. } \\
\left(\mathbf{J}_{\mathrm{I}}\right)\end{array}$ & $\begin{array}{c}\text { SIF } \\
\left(\mathbf{K}_{\mathrm{I}}\right)\end{array}$ \\
\hline 1 & 2 & 0.50 & 0.33 & 0.03734 & 87.59 \\
1 & 3 & 0.33 & 0.33 & 0.04899 & 100.33 \\
1 & 4 & 0.25 & 0.33 & 0.06173 & 112.63 \\
1.5 & 2 & 0.75 & 0.50 & 0.02645 & 73.72 \\
1.5 & 3 & 0.50 & 0.50 & 0.03618 & 86.22 \\
1.5 & 4 & 0.37 & 0.50 & 0.04487 & 96.02 \\
2.0 & 2 & 1.00 & 0.67 & 0.02648 & 73.76 \\
2.0 & 3 & 0.67 & 0.67 & 0.02780 & 75.58 \\
2.0 & 4 & 0.50 & 0.67 & 0.03501 & 84.82 \\
\hline
\end{tabular}

The modeling for compatibility testing of the SIF function was used MINITAB software. The SIF diagram for load stress $\sigma 35,40,60,70,80$ $\mathrm{MPa}$ and crack ratio $\mathrm{a} / \mathrm{W} 0.25,0.33,0.5$ are shown in Fig. 7.

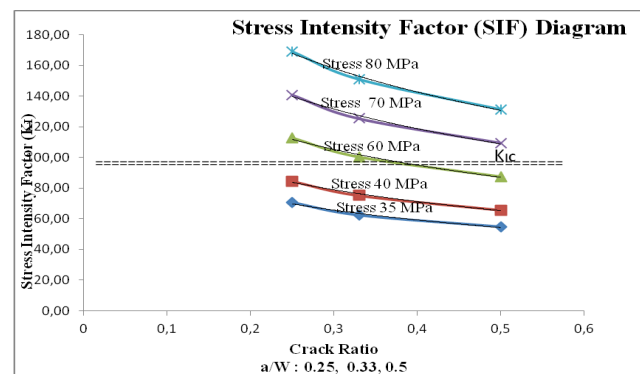

Fig. 7. The SIF Diagram for crack ratio $0.25,0.33$ and 0.5

As shown in Fig. 7, it appears that for the load stress 70 and $80 \mathrm{MPa}$ with a crack ratio a/W 0.25, 0.33 and 0.5 , the SIF are greater than fracture toughness $\mathrm{K}_{\mathrm{IC}} 100 \mathrm{MPa} \sqrt{\mathrm{m}}$ (limit line). It means that for load stress 70 and $80 \mathrm{MPa}$, the material will experience fracture. The curve fitting each are a natural logarithm function with an adjusted residual $\mathrm{R}^{2}$ close to one. The SIF function for similar loads and crack function are in Table 7.
Table 7. The SIF function for crack ratio $0.25,0.33$ and 0.5

\begin{tabular}{ccc}
\hline $\begin{array}{c}\text { Stress } \\
(\text { MPa })\end{array}$ & $\begin{array}{c}\text { Equation } \\
\text { SIF vs Crack Ratio }\end{array}$ & $\mathbf{R}^{\mathbf{2}}$ \\
\hline 35 & $\mathrm{~F}(\mathrm{x})=-19.72 \ln (\mathrm{x})+40.38$ & 1.0000 \\
40 & $\mathrm{~F}(\mathrm{x})=-24.33 \ln (\mathrm{x})+49.50$ & 0.9178 \\
60 & $\mathrm{~F}(\mathrm{x})=-31.52 \ln (\mathrm{x})+64.56$ & 0.9998 \\
70 & $\mathrm{~F}(\mathrm{x})=-36.47 \ln (\mathrm{x})+101.32$ & 0.9891 \\
80 & $\mathrm{~F}(\mathrm{x})=-39.38 \ln (\mathrm{x})+180.74$ & 0.9998 \\
\hline
\end{tabular}

The SIF Diagram for crack ratio a/W in range $0.37,0.5$ and 0.75 shown in Fig. 8.

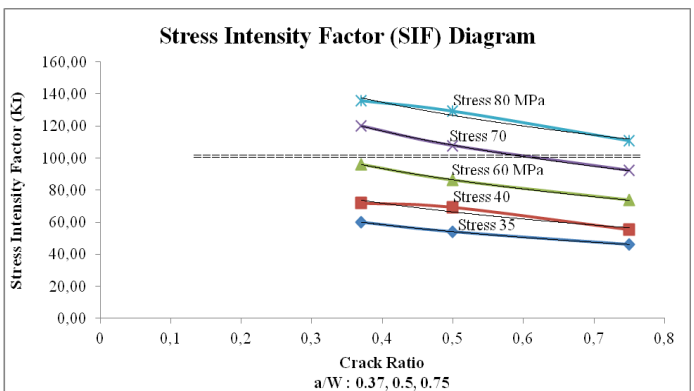

Fig. 8. The SIF Diagram for crack ratio $0.37,0.50$ and 0.75

The SIF diagram in Fig. 8 shows that for the load stress $80 \mathrm{MPa}$ with crack ratio $0.37,0.50$, and 0.75 , the Stress Intensity Factor greater than fracture toughness $\mathrm{K}_{\mathrm{IC}} 100 \mathrm{MPa} \sqrt{\mathrm{m}}$. It means that the material will encounter fracture. Same thing will happen for the load stress $70 \mathrm{MPa}$ with crack ratio 0.37 and 0.50 .

The SIF function for load stress 35, 40, 60, 70, $80 \mathrm{MPa}$ and crack ratio a/W $0.37,0.50,0.75$ are shown in Table 8.

Table 8. The SIF Function for crack ratio $0.37,0.50,0.75$

\begin{tabular}{ccc}
\hline $\begin{array}{c}\text { Stress } \\
(\mathbf{M P a})\end{array}$ & \multicolumn{1}{c}{$\begin{array}{c}\text { Equation } \\
\text { SIF vs Crack Ratio }\end{array}$} & $\mathbf{R}^{\mathbf{2}}$ \\
\hline 35 & $\mathrm{~F}(\mathrm{x})=-22.33 \ln (\mathrm{x})+38.744$ & 0.9817 \\
40 & $\mathrm{~F}(\mathrm{x})=-26.73 \ln (\mathrm{x})+46.713$ & 0.9891 \\
60 & $\mathrm{~F}(\mathrm{x})=-35.70 \ln (\mathrm{x})+62.249$ & 0.9892 \\
70 & $\mathrm{~F}(\mathrm{x})=-44.61 \ln (\mathrm{x})+77.844$ & 0.9892 \\
80 & $\mathrm{~F}(\mathrm{x})=-53.64 \ln (\mathrm{x})+93.493$ & 0.9921 \\
\hline
\end{tabular}

While the curve fitting is approaching a natural logarithm function with an adjusted residual $\mathrm{R}^{2}$ approaching one.

The SIF diagram for the crack ratio of width cracks a/W in range 0.5, 0.67 and 1.0 shown in Fig. 9.

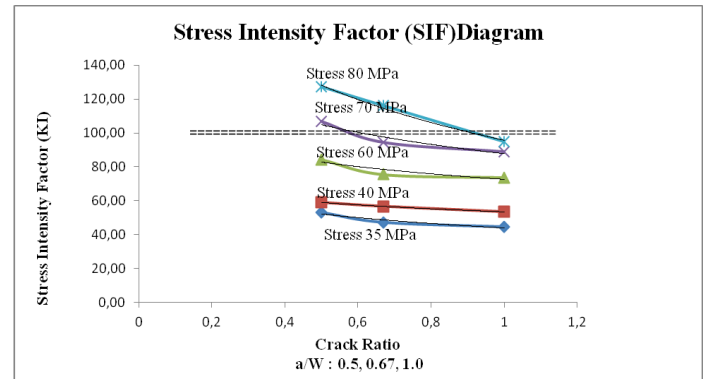

Fig. 9. The SIF Diagram for depth crack 0.50, 0.67 and 1.00 
In Fig. 9, the SIF diagram shows that only for the load stress $80 \mathrm{MPa}$ with the crack ratio a/W 0.50 , 0.67 and 1.00, the SIF are greater than fracture toughness $\mathrm{K}_{\mathrm{IC}}$, which implies that the material will experience fracture. The SIF Function for load stress $\sigma 35,40,60,70,80 \mathrm{MPa}$ and the crack ratio a/W 0.50, 0.67 and 1.00 shown Table 9.

Table 9. The SIF Function for crack ratio 0.50, 0.67 and 1.00

\begin{tabular}{ccc}
\hline $\begin{array}{c}\text { Stress } \\
\text { (MPa) }\end{array}$ & $\begin{array}{c}\text { Equation } \\
\text { SIF vs Crack Ratio }\end{array}$ & $\mathbf{R}^{2}$ \\
\hline 35 & $\mathrm{~F}(\mathrm{x})=-8.013 \ln (\mathrm{x})+53.392$ & 0.9999 \\
40 & $\mathrm{~F}(\mathrm{x})=-11.96 \ln (\mathrm{x})+43.857$ & 0.9131 \\
60 & $\mathrm{~F}(\mathrm{x})=-14.74 \ln (\mathrm{x})+72.548$ & 0.8085 \\
70 & $\mathrm{~F}(\mathrm{x})=-24.72 \ln (\mathrm{x})+87.696$ & 0.9087 \\
80 & $\mathrm{~F}(\mathrm{x})=-47.00 \ln (\mathrm{x})+96.637$ & 0.9924 \\
\hline
\end{tabular}

where the curve fitting are similar to the prior one.

From the analyzed SIF mentioned above, it is understood that the SIF function with the goodness of fit for several crack ratio and load stresses are in natural logarithmic curve. In load stress 70 and $80 \mathrm{MPa} \sqrt{\mathrm{m}}$, RPV material will experience fracture condition. Those values are approaching the fracture toughness (100 MPa $\sqrt{m}$ ), but still have a small margin from the upper limit.

\section{CONCLUSION}

Semi-elliptic surface cracks in reactor pressure vessel wall were analyzed under the 3-D model using SIF and J-integral parameters. Modeling was performed to construct a relationship between crack geometry and stress intensity factor. The SIF values depend on crack geometry, especially the ratio between crack depth and crack surface length. The results showed that the relationship between crack geometry and SIF have the goodness of fit close to one. The SIF of the material SA 508 for load stress 70 and $80 \mathrm{MPa}$ with a crack ratio $0.25,0.33$ and 0.5 on RPV wall are almost greater than the fracture toughness value. It means for load stress 70 and $80 \mathrm{MPa}$ the material will in fracture condition.

\section{ACKNOWLEDGMENT}

The authors are grateful for the financial support from DIPA PTKRN-BATAN (2018).

\section{REFERENCES}

1. Mehrjoo M., Khaji N., Ashtiany M.G. Application of genetic algorithm in crack detection of beam-like structures using a new cracked Euler-Bernoulli beam element. Applied Soft Computing. 2013. 13: 867-880.

2. Perl M., Steiner M. 3-D stress intensity factors due to autofrettage for an inner radial lunular or crescentic crack in a spherical pressure vessel. Engineering Fracture Mechanic. 2014. 131:282-295.

3. Lee K., Jhung M., Kim M., Lee B. Effects of tempering and PWHT on microstructures and mechanical properties of SA508 GR.4N steel. Nuclear Engineering Technology. 2014. 46: 413-422.

4. Zerbst U., Kling C, Clegg R., Fracture mechanics as a tool in failure analysis Prospects and limitations. Engineering Fracture Mechanic. 2015. 55:376-410.

5. Han Q., Wang Y., Yin Y., Wang D., Determination of stress intensity factor for mode I fatigue crack based on finite element analysis. Engineering Fracture Mechanic. 2015. 138:118-126.

6. Perl M., Steiner M., Pery J. 3-D stress intensity factors due to full autofrettage for inner radial or coplanar crack arrays and ring cracks in a spherical pressure vessel. Engineering Fracture Mechanic. 2015. 138:233-249.

7. Peng D., Jones R. A simple method for calculating the stress intensity factors for complex 3D cracks at a notch. Engineering Fracture Mechanic. 2016. 158:81-86.

8. Okada H., Koya H., Kawai H., Li Y., Osakabe K. Computations of stress intensity factors for semi-elliptical cracks with high aspect ratios by using the tetrahedral finite element (fully automated parametric study). Engineering. Fracture Mechanic. 2016. 158:144-166.

9. Livieri P., Segala F. Stress intensity factors for embedded elliptical cracks in cylindrical and spherical vessels. Theory Application Fracture Mechanic. 2016. 86:260-266.

10. Susmikanti M., Himawan R., Hafid A., Hartini E. Evaluation on Mechanical Fracture of PWR Pressure Vessel and Modeling Based on Neural Network. Tri Dasa Mega. 2016. 18: 87100

11. Hartini E., Himawan R., Susmikanti M. Fracture Mechanic Uncertainty Analysis in the Reliability assessment for the reactor pressure vessel : (2D) subjected to the internal pressure. Tri Dasa Mega. 2016. 18:55-64.

12. Susmikanti M., Himawan R., Sulistyo J.B. The Analysis of Optimal Crack Ratio for PWR Pressure Vessel Cladding and using Genetic Algorithm. Tri Dasa Mega. 2018. 20:47-54. 